\title{
La ética del discurso ante el desafío de la filosofía latinoamericana de la liberación*
}

\author{
KARL-OTTO APEL \\ Universidad de Francfort
}

El autor continúa aquí una polémica con Enrique Dussel ya iniciada en trabajos anteriores. A pesar de las diferencias en los puntos de partida y en bastantes de sus planteamientos, se consta- ta la posibilidad de una complementariedad mutua entre la ética de la liberación propugnada por Enrique Dussel y la ética del discurso desarrollada por Karl-Otto Apel.

\section{Introducción: el estado de la cuestión}

Mi ponencia pretende ser la continuación de un diálogo con Enrique Dussel iniciado con anterioridad (Apel, 1992). Al respecto apareció de mi parte hasta ahora sólo una introducción que desgraciadamente no pude continuar enseguida, como estaba previsto. Esto tuvo la desafortunada consecuencia de que mi introducción, que contenía tan sólo reflexiones acerca del posible contenido de la discusión prevista, fue confundida con esta última o por lo menos fue recibida y contestada como si hubiera sido parte de una toma de posición de la ética del discurso sobre la ética de la liberación (véase Dussel, 1994). Esta estimación se refiere especialmente a mis alusiones - por cierto no libres de prejuicios- sobre la teoría del valor-trabajo de Karl Marx, y su relación con la teoria económica de la dependencia.

En mi ponencia de hoy no trataré primero -o no trataré inmediatamente- esta temática central y concreta de la filosofía de la liberación, sino abordaré primero las aportaciones de Enrique Dussel en las que él intenta por sí mismo relacionar y explicitar la ética de la liberación y la ética del discurso. Aquí pertenecen, en primer lugar, las siguientes aportaciones: a) "La comunidad de vida y la interpelación del pobre" (ponencia de Friburgo; véase Dussel, 1990); $b$ ) «La razón del Otro. La interpelación como acto de habla» (México; véase Dussel, 1991); y c) "Del escéptico al

\footnotetext{
* Este artículo fue presentado por K.-O. Apel en el XIX Congreso Mundial de Filosofá en Moscá y en Säo Leopoldo (Brasil) en 1993, bajo el titulo *Die Diskursethik vor der Herausforderung der lateinamerikanischen Philosophie der Befreiung*. La traducción es de Maria Brumm R. Isecorfa publicara en el número 13 la respuesta de Enrique Dussel, "Ia ática de la liberación ante la ética del discurso*.
} 
cínico (Del adversario de la ética del discurso al adversario de la filosofía de la liberación)" (Maguncia; véase Dussel, 1992).

\section{Nuevo punto de partida: la imputación heuristica de una relación de complementación}

En sus tres aportaciones al diálogo Enrique Dussel produjo pruebas asombrosas e imponentes de su voluntad y capacidad de apropiación comprehensiva del juego linguiístico de la ética del discurso, para ser más exacto, del juego lingüístico del giro post-lingüistico (post-linguistic tum), de la pragmática universal y de la pragnática trascendental respectivamente. Tres veces, de diferente manera, intenté comprobar una relación complementaria entre el punto de partida de la ética del discurso y el de la ética de la liberación, una relación de complementariedad aceptable, por decirlo así, por ambas partes. Así, por ejemplo, plantea en su primera aportación una relación complementaria entre la "comunidad ideal de comunicación" como requisito anticipatorio de la pragmática lingüistica trascendental y la "comunidad ideal de vidas como requisito anticipatorio de una filosofia trascendental de la liberación que incluiría también una «economía trascendental»; así, en su segunda aportación, establece una relación de complementariedad entre la "interpelación a la razón del otro" en el discurso argumentativo y la interpelación correspondiente del "otro", quien está excluido de la comunidad real de comunicación, el upobre" del Tercer Mundo, por quien pretende abogar la ética de la liberación; así finalmente en su tercera aportación, hay una relación complementaria entre la refutación pragmática-trascendental del escéptico al servicio de la última fundamentación de la norma básica de la ética del discurso, y la lucha intelectual de la ética de la liberación contra el cínico, esto es, contra la racionalidad estratégica del sistema capitalista dominante que ni siquiera entabla relaciones de discurso con el otro, marginado.

En vista de estos intentos de mediación de Dussel que caractericé a grandes rasgos, quisiera constatar, en primer lugar, que estoy a favor también de la posibilidad de una complementariedad mutua entre la ética de la liberación y la ética del discurso. Y como heuristica de una comparación crítica de ambos puntos de partida, la concepción de Hans Schelkshorn (véase Schelkshorn, 1992), a quien puede considerarse hoy el conocedor más comprobado de ambos puntos de vista, se me hace la más plausible. Schelkshorn reconoce claramente el diferente punto de partida de ambas éticas que, claro está, tiene que ver mucho con su ubicación geográfica e histórica, pero de ninguna manera puede reducirse a ella de manera relativista; mucho menos en el sentido de una puesta en evidencia a priori de la ética del discurso como una ideología de la comunidad de comunicación real dominante, ésta es del Norte, o del capitalismo. Según Schelks- 
horn, existe más bien una diferencia relevante metodológica, en primer lugar, entre las dos éticas, según sus diferentes situaciones, de tal manera que se puedan corregir mutuamente en sus ventajas y debilidades, mas no puede excluir una a la otra. Quiero caracterizar brevemente esta constelación en lo siguiente con mis palabras.

\subsection{El punto de partida de la ética de la liberacion: la evidencia vivencial ética de la "interpelación del pobre»}

La ventaja de la ética de la liberación está en su experiencia auténtica de la miseria y la excomunión de los pobres de este mundo; esto quiere decir la exclusión de aproximadamente el $75 \%$ de la humanidad de casi todos los discursos relevantes que la conciernen en las áreas de la política, la economía y la cultura. De esta experiencia de la «exterioridad» (Levinas) de los derechos del otro, resulta -muy similar al caso de la experiencia del proletariado de los jóvenes Marx y Engels - una evidencia para la toma de partido necesaria y ética, que a primera vista hace parecer superflua cualquier fundamentación ni se diga una fundamentación última (de la validez intersubjetiva) de las normas éticas, inclusive la hace parecer un escape ideológico. El "grito» de los hambrientos y oprimidos forma el punto de partida de su "interpelación", la que tendrá que elucidarse aún; este "gritow es de hecho un reclamo de hacer valer los derechos a priori, intersubjetivamente válida (con obligatoriedad intersubjetiva). En este sentido, el punto de vista de los oprimidos siempre es el punto de vista de la humanidad en tanto pauta ética. En esto consistió, como ya dije, la evidencia original de la toma de partido de Marx a favor del proletariado y en ello consiste hoy en día, en el conflicto Norte-Sur, la evidencia de la exigencia ética que se expresa en la cara del pobre, según Levinas y Dussel respectivamente, al «irrumpir Dios en la vida" (Levinas) - especialmente también en la vida de los satisfechos y complacidos.

Pero en la medida en que la interpretación ética política y empírica de las ciencias sociales intercede a favor del "derecho" interpelativo de los pobres y marginados y trata de guiar la "praxis de la liberación", en esta medida se vuelve problemática la toma de partido y la formación de teorías que se vincula a ella. En este momento necesita la fundamentación normativa de su justeza, por principio, así como de la responsabilidad de sus consecuencias. Esto no sólo vale para una fundamentación última filosófica de los principios del discurso, sino también para una constante intervención a través de los discursos de los afectados -en tanto posible-y de las ciencias sociales empíricas.

Hay que admitir y hasta enfatizar que la filosofía de la liberación, en el discurso ahora necesario, tiene la tarea de recordar constantemente la evidencia de la interpelación justa de los pobres; además tiene la tarea de la 
crítica ideológica de la filosofía y ciencias sociales dominantes, especialmente de la economía. No obstante la evidencia original de su parcialidad ética, en la medida de su elaboración relevante teórica y práctica, corre el riesgo del dogmatismo, inclusive de una posible perversión en el sentido de un terrorismo que pueda recaer en los pobres de manera muy sensible. Quiero decir que el riesgo de un desarrollo así se puede estudiar muy bien no sólo en la elaboración teórica e implementación práctica del marxismo, sino también en los intentos de una realización político-económica de la liberación del cuasi-proletariado del Tercer Mundo. No pienso sólo -pero tambiénen Pol Pot o el Sendero Luminoso de Guzmán, sino en los intentos muy respetables, en mi opinión, de Fidel Castro y los Sandinistas. No es completamente ajeno querer atribuir el fracaso de muchos de estos intentos a los errores o hasta faltas de sus iniciadores. Más bien me es importante constatar, en primer lugar, que la filosofía de la liberación no puede simplemente derivar de la indudable evidencia de su punto de partida empírico a la vez que ético, una primacía de evidencia concreta y de validez intersubjetiva para elaborar sus teorías e implementarlas en la práctica. La filosofía de la liberación pronto se topa en esta área problemática de la verificación con el riesgo de falibilidad, del mismo modo como todos los demás intentos de filosofía macro-ética y de las ciencias sociales críticas, pero también, como veremos, con la problemática de la aplicación de la ética del discurso.

En el caso de la ética del discurso, sin embargo, la estructura arquitectónica de las ventajas y desventajas más bien lleva acentos contrarios. Pues ella parte del punto de vista filosófico-trascendental-esotérico de la última fundamentación de la validez en general. Aquí tiene su base evidencial desde la cual va emprendiendo la aplicación de argumentaciones, cont sus reglas de procedimientos, en situaciones específicas - tanto geográficas como históricas; desde allí emprende también la crítica de normas morales o discursos prácticos de legitimación. Permítanme explicar este enfoque de la ética del discurso un poco más detalladamente.

\subsection{El punto de partida de la ética del discurso: la fundamentación ültima trascendental-pragmática rompe el bloqueo de la racionalidad ética causado por el cientismo y el relativismo}

Desde un principio la ética del discurso fue concebida -al menos en el caso de la pragmática trascendental- como macro-ética referida al planeta. De ninguna manera, ni antes, ni ahora, está orientada hacia el problema intra-académico de la fundamentación última como refutación del escéptico, sino que se orienta, desde un principio, hacia la cuestión de cómo superar las consecuencias a nivel mundial de la ciencia y técnica contemporáneas - por ejemplo la crisis ecológica- a través de una ética de responsabilidad de validez universal. 
Sin embargo, este problema me ha obligado a preguntar por una posible fundamentación última de la ética. En los dos frentes del análisis di con el escéptico como opositor posible, no de manera inmediata, pero sí en última instancia. Resulta que el escéptico es, desde los tiempos antiguos, el interlocutor decisivo en las indagaciones de las condiciones de posibilidad de una filosofía intersubjetivamente válida, no importando su motivación a su ubicación histórico-geográfica. Esto significa: si no pudiéramos refutar al escéptico, entonces la argumentación válida $-\mathrm{y}$ esto es la filosofia y la ciencia- sería imposible de antemano. Sí podemos, en cambio, refutar al escéptico comprobándole que él mismo tiene que presuponer y utilizar necesariamente las condiciones normativas del discurso en su argumentación y que no puede negar esto sin caer en una contradicción performativa: si podemos comprobarle esto - no sin contar de su parte con la reflexión de buena voluntad sobre las presuposiciones de su argumentación- entonces no sólo hemos refutado al escéptico, sino que hemos ganado una base indiscutible para la argumentación en la filosofía y la ciencia: no se ha ganado un sistema de axiomas para deducciones racionales de teoremas como lo esperaba el racionalismo clásico; sin embargo se tiene una condición trascendental-pragmática (esto es no lógicosemántica sino dialógico-dialéctica) para la presentación y defensa argumentativas de cualquier axioma de posibles teorías.

Lo éticamente relevante de este argumento trascendental pragmático desde un principio no sólo consistió en fundamentar la validez de la argumentación filosófica en general por el camino de la refutación del escéptico, sino que consistió en probar que el reconocimiento de ciertas normas éticas fundamentales forma parte de las condiciones normativas de la argumentación. Se reconoce, por decirlo así, la ética de una comunidad ideal de comunicación que consiste en normas básicas, entrelazadas entre sí, en el sentido de mismos derechos, misma responsabilidad, esto es de solidaridad por parte de todos los interlocutores posibles -en alto contraste, por ejemplo, con la defensa amoral del interés propio en un discurso de negociación estratégica (también con un contrato a lo Hobbes). El punto principal ético de la pragmática trascendental reside en una inteligencia que fue imposible aún para la filosofia del sujeto de la Edad Moderna -Descartes, Kant y Husserl-. Reside en la inteligencia de que la frase no-falsificable de "Yo pienso" ("ego cogito") no puede entenderse como trascenden" talmente solitaria y autárquica en el sentido del solipsismo metódico (en este caso no podría ni siquiera expresarse/decirse) sino que debe entenderse como "yo argumento en el discurso" y esto quiere decir: argumento como miembro de una comunidad real de comunicación (determinada históricamente) a la vez que como miembro de una comunidad comunicativa ideal e ilimitada (por lo tanto abierta hacia el futuro) y necesariamente anticipada contrafactualmente. 
Con base en esta reflexión, creo, me fue posible romper el bloqueo a la fundamentación racional de una ética con validez universal en dos frentes de una discusión entendida como global:

Primero - para empezar con lo histórico- en vista de la monopolización ampliamente aceptada de toda racionalidad fundamentadora por parte de la racionalidad de la ciencia neutra de valores (y de la racionalidad instrumental y estratégica que ésta idealmente presupone, también neutra de valores), aquí se ha podido demostrar que aún la racionalidad científica neutra de valores, en la dimensión sujeto-objeto, presupone, en la dimensión sujeto-cosujeto de la comunidad argumentativa de los cientificos, la ética solidaria ya esbozada de la comunidad ideal de comunicación. De modo que, creo, especialmente en los últimos tiempos, ha podido demostrarse que también se puede romper el bloqueo historicista o cultural-antropológico relativista de la fundamentación racional de una ética válida universalmente. ¿Cómo se puede demostrar esto? Así por ejemplo:

La argumentación del relativista se sirve necesariamente de la diferenciación y la interdependencia entre el a priori de la comunidad comunicativa real e ideal: en relación a la primera se refiere con razón a la dependencia cultural histórico-geográfica y a la parcialidad de cualquier persona que argumenta -este también en el sentido de su dependencia no-reflexionada de una tradición moral particular. Aquí el relativista es heredero del racionalismo histórico-hermenéutico y etnológico-antropológico. Pero por el simple hecho de argumentar y de ser capaz de reconocer la relatividad cultural como límite de la aspiración a la validez universal, el relativista tiene que presuponer y a la vez dirigirse de cierta manera a la instancia de reflexión metahistórica de la racionalidad universalmente válida de la comunidad del discurso ideal e ilimitada.

Esto se muestra por ejemplo en el título provocador del libro de A. MacIntyre Which rationality, whose justice? Este título por un lado alude a la tesis del libro: que no puede haber una racionalidad ni justicia universalmente válidas. Pero al mismo tiempo, si pretende tener sentido como provocación del discurso, tiene que dirigirse justamente a la instancia racional universal y servirse de ella como instancia de decisión en la cuestión suscitada. En esta medida el título del libro expresa una contradicción performativa.

\subsection{El reproche de la crítica ideológica del eurocentrismo}

Con esta defensa de la reivindicación de la universalidad de la filosofía en general no se ha demostrado de ninguna manera que les asiste el derecho a todas las reivindicaciones de universalidad de la filosofía tradicional -esto es de la filosofía orientada hacia Europa, en primer lugar. En este punto la fundamentación ética trascendental-pragmática más bien entra 
en una posible confrontación con la ética de la liberación. Aquí se encuentra, con buenas razones histórico-empíricas, con el reproche del eurocentrismo de las reivindicaciones de universalidad de la filosofía europea o europea-norteamericana. Y este reproche no sólo tiene un significado teorico-epistemológico, sino también un significado ético-político. Los representantes de la filosofía de la liberación agudizan este reproche a veces hasta llegar a ver la tradicional dependencia de la filosofia latinoamericana de la filosofía europea - desde la escolástica ibérica pasando por el positivismo del siglo $\mathrm{XDX}$ hasta la filosofía analítica y el posmodernismo-como la dimensión ideológica de la dependencia general, político-económica del capitalismo en la cual se encuentra la periferia (el Sur) con respecto al capitalismo hegemónico del centro (del Norte). Vista de esta manera la filosofía latinoamericana en su conjunto no sólo cae en el reproche de la inautenticidad, sino, más allá, inclusive en el veredicto de ser co-culpable del encubrimiento y la suplantación de la miseria y la enajenación de los pueblos del Tercer Mundo -en Latinoamérica especialmente de los indigenas, mestizos y mulatos.

Aquí otra vez no se puede negar la similitud con la crítica de la ideología del materialismo histórico de Marx y Engels. Y dicho sea de paso que en esta similitud se expresa naturalmente, de nuevo, una dependencia de la filosofía europea. Pero no quiero usar esta observación un poco maliciosa de manera inmediata como argumento contra la filosofía de la liberación. Más bien quiero tomar en serio la crítica ideológica y por lo tanto ético-política de la sospecha del eurocentrismo y hasta la acepto en un sentido que voy a precisar más adelante. ¿Cuál es la posición de la ética del discurso ante la crítica ideológica cuasi-marxista del eurocentrismo?

\subsection{La pragmática trascendental está a favor de la crítica de la ideología, pero en contra del "historicismo" de Marx}

La Escuela de Frankfurt de la llamada "teoría critica" a la cual me siento perteneciente - aunque un poco marginado- ciertamente lleva el cuño de la crítica de la ideología inspirada por Marx, como es sabido. Yo mismo introduje por los años setenta el a priori de la relación dialéctica entre la comunidad de comunicación real e ideal, entre otras razones porque queria de antemano eliminar toda sospecha de ideología, crítica sociocultural. Más exacto: la introducción del a priori de la comunidad de comunicación real, determinada históricamente, quiso ser el resumen de mi anterior recepción y reconstrucción de la comprensión tanto hermenéutica como crítico-ideológica de la dependencia de cualquier sujeto de argumentación de su «comprensión del mundo determinada por su ser» (Karl Marx o Karl Mannheim o Heidegger o Gadamer).

Claro: la idea que afirmé como simultáneamente válida de que la ar- 
gumentación no puede prescindir de la idea reguladora y la anticipación contrafáctica de la pertenencia a una comunidad ideal de comunicación, esta afirmación mía tenía y tiene una función correctiva trascendental-filosófica: pretende impedir el racionalismo excesivo hermenéutico y de crítica ideológica en el sentido del hermeneuticismo y del historicismo. Y tengo que insistir, por lo menos para el propio Marx, no así para la recepción de Marx por Dussel, en la siguiente tesis: desde los escritos de juventud de los años cuarenta Marx, a la vez que introduce el esquema de base y superestructura abandona por completo (en mi opinión por incomprensión) la cuestión trascendental-filosófica, proveniente de Kant, de las condiciones posibles de validez intersubjetiva. Esto naturalmente afectố las reivindicaciones de validez de la misma filosofía social, historico-materialista. Sin embargo, Marx conservó el reclamo heredado de Hegel que la «realidad» histórica se concibe «razonable» —quiere decir determinada por una «ley de movimienton. De ahí resultó -especialmente en el Marx maduro de $E l$ Capital - el "historicismo", llamado así por Popper. Yo entiendo por esto una posición en la que, por un lado, en correspondencia a la «moralidad sustancial» de Hegel, se relativiza la moral históricamente como usuperestructura" de cada una de las formaciones sociales, cada una determinada históricamente y concluida como totalidad-, y por otro lado, sin embargo esta posición persevera en la predictibilidad incondicional de una realidad mejor que vendrá a sustituir la presente, y en esta prognosis enfática esconde, hasta cierto punto, el compromiso moral para un deber incondicional, que no es históricamente relativo.

Ahora bien: ¿cómo ve Enrique Dussel la relación entre relativismo histórico y filosofía trascendental?

\subsection{La posición de la ética de la liberación como combinación del historicismo de Hegel-Marx-Heidegger con la exigencia ética incondicional en el sentido de Levinas}

En la Filosofía de la Liberación de Enrique Dussel me parece encontrar una clara analogía con la concepción de la historia de Hegel y Marx. También él comprende la "moral" - mejor dicho las "morales", como pertenecientes y relativas a "totalidades» del ser que se concluyen históricamente. Según Dussel, a esto corresponde la visión existencial-ontológica-hermenéutica de Heidegger de la relatividad de nuestra entera comprensión del mundo en el sentido del «Ser» condicionado históricamente, 0 «mundos de la vida». Si Dussel hubiera partido nada más de esta concepción, entonces se hubiera enredado, a mi manera de ver, en la aporía típica del marxismo ortodoxo, que consiste en que no puede justificar su compromiso ético, sin duda enfático y estimulante, sino únicamente por referencia a la ley de movimiento de la historia que está científicamente validada. 
Pero Dussel rechaza comprensiblemente el giro hacia el shistoricismo éticon o "futurismo" (afirmando, sin embargo, que en Marx éste no existe, lo cual me resulta incomprensible). En cambio introduce, junto con Levinas, la concepción de la «exterioridad del otron como origen utransontológicon, extrahistórico de la reivindicación incondicional de la ética" (en contraste a la "moral" histórico-relativa). La referencia a esta reivindicación incondicional permite a Dussel disolver todas las "totalidades" del mundo de la vida y su moral relativa a la cultura, totalidades social y ontológicamente determinadas - a favor del imperativo categórico: «iLibera al pobre!n.

En mi opinión, él retoma el pensamiento judeo-cristiano -o como él dice: el pensamiento "semítico»- y de cierta manera lleva a la superficie el punto escondido, encubierto pseudocientíficamente en El Capital, de la toma de partido de Marx por el proletariado: aquí habría que recordar que el joven Marx mismo en su Critica de la filosofia del derecho de Hegel de 1843 formuló explícitamente un "imperativo categóricon como sigue: «Derribar todas las condiciones que hacen del hombre un ser humillado, esclavizado, abandonado y despreciado».

¿Cómo podriamos ahora determinar la posición de la ética del discurso con respecto a esta última posición de la filosofía de la liberación? o, para preguntar con más agudeza: ¿con respecto a la combinación de una ontología de Hegel-Marx-Heidegger de las "totalidades" del ser que concluyen históricamente, inclusive la correspondiente "moral" histórico-relativa, por un lado y por el otro, la reivindicación ética incondicional que irrumpe desde afuera en los mundos de la vida histórico-relativos de manera "transontológica" a través de la "interpelación del otro"?

Intentaremos contestar esta pregunta sucesivamente, partiendo de la fundamentación última trascendental-pragmática de la ética del discurso.

\subsection{La arquitectónica de la "metafisica transontológica" de Dussel desde el punto de vista de la "parte A de fundamentacion" de la ética del discurso}

Para empezar está claro que la exigencia básica de respetar incondicionalmente la uinterpelación del otro" - por ejemplo del pobre del Tercer Mundo- es igualmente válida para la ética del discurso; esto quiere decir, tomarla por principio como aportación innovadora de la argumentación al discurso ilimitado de la comunidad ideal de comunicación postulada. Ya que la norma básica formal y de procedimiento de la ética del discurso prescribe que en todos los casos de problemas éticos relevantes - por ejemplo, en casos de conflicto- hay que considerar los intereses de todos los afectados -y no sólo los intereses de los que en este momento están directamente involucrados en el conflicto-, hay que incluirlos como dere- 
chos válidos en el «discurso práctico». Luego entonces hay que examinarlos en una argumentación sin violencia en cuanto a su razón de ser. Esto es: a) en cuanto a su compatibilidad con los intereses o reclamos de todos los demás afectados, y $b$ ) en cuanto a su posible realización en vista de las características empíricas de la situación y de la responsabilización de las consecuencias principales y secundarias que resulten de su realización. Todo esto se subordina de antemano al objetivo inmanente al discurso que es llegar al entendimiento y al consenso -en caso necesario, cuando no se puede llegar a un consenso, a un compromiso no condicionado estratégicamente.

Ya en el nivel de estos postulados que, de manera simplificada, forman la parte A de fundamentación de la ética del discurso se suscitan algunos motivos posibles o incluso necesarios para discutir la ética de la liberación de Dussel. Se entiende, por ejemplo, que la ética del discurso presupone el que es posible, por principio, que representantes de intereses encontrados -individuos y grupos- se comuniquen en discursos noestratégicos y lleguen a un consenso, esto es que a pesar de todas las dificultades se den discursos de entendimiento entre personas que pertenecen a diferentes clases, razas y formas de vida socioculturales. Esta presuposición principal vale con un límite previsto a priori, como se mostrará más adelante, pero está de antemano en oposición a una cierta sobredramatización de la idea de las "totalidades» del ser que se cierran hacia el exterior y sólo pueden romperse por acciones revolucionarias, como por ejemplo la forma de vida y la moral interior del capitalismo del Norte, hoy dominante. Tendré que regresar a este punto.

En este contexto tengo que abordar primero las condiciones de posibilidad del entendimiento hermenéutico, ya que estas condiciones desempeñan un papel importante en el campo de la problemática ética -también según Dussel. Así, por ejemplo en la relación de la civilización blanca dominante, incluyendo las élites blancas de Latinoamérica que de ella dependen con la cultura popular de los indios —o también de los mestizos y mulatos.

Yo mismo llegué, tal vez como Enrique Dussel, a la problemática ética desde la hermenéutica. En el camino partí, entre otros, también de Heidegger y Gadamer, pero pronto me distancié de estos pensadores en el nombre de una hermenéutica trascendental. Esto significa que en el presente contexto puedo admitir que nuestro entendimiento del otro - particularmente de una forma de vida socioculturalmente ajena- está determinado en una medida empíricamente esencial por la «comprensión del mundo" de la propia forma de vida y tradición cultural. En este sentido Enrique Dussel puede presuponer el concepto del mundo de la *ontología existencial" de Heidegger y también el de la "historia del ser", concebido más tarde por el mismo Heidegger, y puede, con Levinas, llamar el "derecho" 
del "otro» "transontológico» (y en este sentido "metafísico»). Justamente por la "exterioridad del otro" se trasciende el horizonte del entendimiento del ser de una totalidad histórico-ontológica y se cuestiona éticamente.

Pero me es difícil seguir la especulación histórico-filosófica de Dussel sobre esta relación (la de la ontología histórico-hermenéutica o limitada por la forma de vida por un lado, y la ética trascendental - por su fundamentación transontológica- por otra parte): a saber, como una relación de contraste entre la filosolía de Occidente orientada por Grecia, inclusive la dialéctica de la identidad (desde Platón hasta Hegel; o hasta Heidegger) y la filosofía "semítica" vista como una analéctica que trasciende una dialéctica de identidad -en el sentido de la analogía del ser de diferentes personas. Aclarando: me sería comprensible todavía, si Dussel calificara el todo del mundo de la vida presente (del capitalismo) de uno-verdadero" hablando con Adorno y si él abogara con respecto a esta «totalidad del ser» por una «dialéctica negativa" de lo "no-idéntico», siguiendo con Adorno. Pero para mí es de dudar si con ello realmente se ha trascendido la adialéctica ontológica» desde el Platón tardío hasta Hegel -la dialéctica de la inseparabilidad de identidad y no-identidad.

En mi opinión está claro que Platón y más Hegel con el todo del Ser y su verdad comprensible en el Logos justamente no pensaban un "horizonten del "entendimiento del ser" limitado y determinado históricamente en el sentido de Heidegger, sino que pensaron el Todo de los horizontes del entendimiento del ser imaginables - y de ahí la inseparabilidad del ser (como identidad) y del no-ser (como la otredad). Esta concepción del Todo y de la identidad de la dialéctica ontológica de Platón y más completa en Hegel no puede equipararse asi nada más con la filosofia de la historia del mismo Hegel, que sin duda es eurocentrista y por lo tanto se puede relativizar históricamente en su validez. Más bien lo que importa aquí es si toda argumentación filosófica no tenga que pensar el Todo de toda posible verdad referida a un logos - y esto con mayor razón cuanto se cree capaz de considerar por principio el cuestionamiento crítico de totalidades limitadas del entendimiento del ser del otro-, el interlocutor. (En estas condiciones, claro está, no se puede concebir la Nada absoluta y tampoco la creación divina del mundo «ex-nihilom. Pero después de todo, ¿se puede pensar esto filosóficamente, acaso en una filosofia semítica?)

Yo mismo he defendido la tesis de que en nuestro tiempo, la función metodológica de la prima philosophia ya no le corresponde a la ontologia (la metafísica ontológica en el sentido de Aristóteles y sus comentaristas), ni tampoco le corresponde a la filosofía trascendental del sujeto consciente (en el sentido de Kant o Husserl), sino que hoy esta función le compete a una semiótica trascendental o pragmática lingüística. Desde esta perspectiva puedo comprender muy bien que el entendimiento del ser en el sentido de un "mundo de la vida», determinado históricamente, y particularmente los 
juicios de valor inherentes en el sentido de una "moral sustancial" puedan cuestionarse radicalmente por la "interpelación del otro» en el discurso y esto sucede ciertamente al intentar llegar a un entendimiento de diferentes formas de vida socioculturales. El otro es en alguna medida el sujeto (al menos como representante) de otra constitución del sentido del mundo. Pero me pregunto: $¿$ puede esto significar que el entendimiento del ser del otro sea tan diferente del mío que rebase toda identidad imaginable de una totalidad? ¿No contradiría esto también la concepción de "analítica" de Dussel (que se apoya en la "analogia entis" teórica aristotélica)? O -para regresar al problema de la hermenéutica trascendental: ¿se puede preguntar, después de todo, significativamente por las condiciones posibles del entendimiento válido, si no partimos con Hegel de que podamos presuponer la identidad de una razón en el otro y en nosotros, por principio -aunque nunca se pueda saldar empíricamente?

Mis reflexiones hasta aquí acerca del intento de confrontar la ética del discurso y la filosofía de la liberación partieron todas de la presuposición -en el sentido de la parte A de fundamentación de la ética del discursode que los discursos de entendimiento son posibles, por principio; que siempre se puede contar con la buena voluntad para un entendimiento en el discurso, aun en el caso de intereses contrarios. Por lo tanto todas mis anteriores reflexiones -incluyendo mi defensa de una hermenéutica trascendental- eran todavía parte de una discusión con el escéptico. Pero, ¿qué pasa cuando no se puede contar con la buena voluntad para un entendimiento discursivo por parte de los dominadores en el caso de intereses profundamente contrarios - más exacto: en el caso de intereses contrarios que, aunque son ideológicamente velados y prácticamente reprimidos, pero no por eso menos efectivos, como por ejemplo entre dominadores y dominados, explotadores y explotados?

Enrique Dussel presenta este caso como el relevante para la filosofía de la liberación al sustituir al escéptico -adversario idealmente típico de la ética del discurso- por el cínico. ¿Qué puede decir la ética del discurso al respecto? ¿No será el caso que, como ética deontológica de principios ideales de deber, dependa de antemano de la buena voluntad de todos los posibles interlocutores, por más escépticos que sean?

\subsection{El desafio particular a la ética del discurso por parte de la ética de la liberación: el adversario no es el "escéptico", sino el "cinico"}

En un sentido esto es cierto, como por ejemplo en el nivel de la discusión filosófica sobre la fundamentabilidad o aplicabilidad de la ética del discurso, verbigracia el caso de nuestra discusión presente entre la ética de la liberación y la ética del discurso.

¿Pero qué significaría si el escéptico se negara simplemente al discur- 
so desde este nivel? Esta posibilidad se ha aducido muchas veces -entre otros por Jürgen Habermas- como argumento en contra de la posibilidad de una fundamentación última de la ética del discurso. Sin embargo, Dussel reconoce claramente que un escéptico, quien se niega por principio al discurso, deja de ser un "escéptico». Sería imposible conocer la posición filosófica del escéptico si todos los escépticos rehusaran constantemente el discurso. En este sentido está claro que este argumento no puede indicar una aporía de la fundamentación trascendental-pragmática de la ética del discurso. Quien se niega por principio a entrar al discurso no puede argumentar - y por lo tanto rigurosamente no puede ni siquiera pensar con un reclamo de validez intersubjetiva. Es "casi como una planta», como ha anotado Aristóteles al respecto.

Pero no tiene que significar esto. El escéptico puede rehusar el discurso por motivos estratégicos, como por ejemplo para no poder ser refutado. Entonces se vuelve cínico, quien, por cierto, suele tener otros motivos adicionales de por qué se niega a las refutaciones discursivas, por ejemplo, motivos de interés propio político-económico. Más aún, el escéptico convertido en cínico, ya no puede argumentar: por lo tanto no puede, para repetirlo, cuestionar la fundamentación de la ética del discurso. Al no poder cuestionar la aplicabilidad práctica de la ética del discurso, ¿no se seguiria de ahí la diferencia prácticamente relevante entre la ética del discurso y la ética de la liberación - de tal manera que sólo la última partiría de una posición realista en la presente situación mundial?

Me parece que esta pregunta contiene el meollo del reto de la ética del discurso por parte de la ética de la liberación latinoamericana; a primera vista (prima facie) podría parecer que la ética del discurso al basarse en una fundamentación última trascendental-pragmática tenga que caer aquí en la ingenuidad. Peor aún: según Enrique Dussel el «filósofo de la pragmática trascendental" al "empezar realmente a argumentar con el escéptico" se encuentra "ya (no sólo "empíricamente", sino "realmente") dentro de un sistema en el que domina la razón cínica. La acción argumentativa de la ética del discurso cumple una "función" dentro del sistema al verse confrontada en la realidad solamente con el escéptico, el académico, el científico (que puede ser un "funcionario" de la razón cínica), mas no descubre a su verdadero adversario más profundo: la "razón cínica" misma que domina o controla el sistema de la totalidad" (p. 12, Ms.).

$\mathrm{Si}$ esto fuera cierto entonces todos aquellos quienes hacen un discurso filosófico sobre la relación de la ética del discurso y la ética de la liberación - esto incluiría al propio Enrique Dussel y a todos nosotros participantes en la presente discusión - no serían más que «idiotas útiles» (Lenin) del existente sistema capitalista mundial, no sólo por la posibilidad empírica, sino "de hecho». La única "praxis de la liberación" significativa sería la guerra, la guerra civil mundial. Esto lo afirma Dussel en un lugar importante, pero lo 
niega en otros - a favor de posibles reformas y hasta de la posible utilización de la ética del discurso por parte de la ética de la liberación que es la que debe acompañar de manera inmediata la praxis de la liberación como su «concientización» en el sentido de Paulo Freire (pp. 14 s. y 17 s.).

Ante este cuestionamiento filosófico más radical ¿cuál es cen realidad» la posición de la ética del discurso? A pesar de la actualidad explosiva del problema vamos a intentar argumentar pedantemente y por pasos.

\subsection{El paso del "escéptico" al "cinico» desde el punto de vista de la "parte $B$ de fundamentación" de la ética del discurso}

A. Para empezar tengo que impugnar el que la «acción argumentativa de la ética del discurso" no sólo por posibilidad empírica, sino de manera "real" cumple una "función" dentro del sistema» (del capitalismo) por ser posiblemente el escéptico como académico nada más que un "funcionariom de la razón cínica. Tales argumentos se han aducido muchas veces en contra de la pragmática trascendental, aunque en forma académica menos grave. Por ejemplo se ha señalado que los interlocutores -escépticos y otros-pueden tener en cualquier momento una motivación estratégica tal que sólo aspiran a instrumentalizar el discurso en el que participan para sus fines (así por ejemplo el discurso de expertos científicos puede instrumentalizarse político-estratégicamente). (A. Leist.)

La respuesta trascendental-pragmática a este argumento dice: si el que argumenta así (Dussel, Leist o quien quiera que sea) está dispuesto a reflexionar estrictamente sobre lo que él mismo presupone como intención de la argumentación, entonces reconocería que, como representante de la argumentación seria, sin condiciones estratégicas, no puede pertenecer a los funcionarios de la razón estratégica o hasta cínica, señalados por él mismo tan sólo por argumentar («for argument's sake»); comparado con estos funcionarios él tiene que estar, por principio, en un nivel de reflexión más alto: en el nivel de reflexión de aquellos quienes - sin condiciones estratégicas-, elaboran el curso (filosófico) que es el único que puede diferenciar la razón estratégica de la comunicativa y por lo tanto - con Dussel- puede discernir también el escéptico del cínico. De aquí resulta una separación analítica muy tajante entre aquellos con los que se puede y debe discutir -incluyendo al escéptico que es un interlocutor necesario- y los representantes reales de la racionalidad cínica sobre los que se puede y debe discutir, como sobre todo lo demás.

Con esto queda claro que el discurso argumentativo en el sentido de la ética del discurso, trasciende siempre y necesariamente cualquier «sistema totalitario" en el sentido de Dussel - al igual que el derecho del otro en el sentido de Levinas. Aquí no puede haber una prioridad unilateral, sino sólo la prioridad de un despertar, en el sentido de una motivación concreta, 
por una parte y la fundamentación última de validez - también de la validez de normas éticas básicas-, por otra parte. Resumiendo: la ética de la liberación y la ética del discurso a priori necesitan una de la otra.

B. ¿No empieza la impotencia intelectual de la ética del discurso justamente en donde uno tiene que ver "realmente" (Dussel) con el cínico, o sea el representante de la "voluntad de poder», en donde sólo puede ayudar la práctica del «contrapoder» (Foucault)?

Tampoco esta suposición es pertinente, en mi opinión. Esta suposición no toma en cuenta o malinterpreta la parte $B$ de la ética del discurso que está prevista ya en la fundamentación última trascendental-pragmática. Esta parte está prevista a priori en el sentido de que está claro de antemano que la separación estricta, postulada en la parte $A$, entre la racionalidad discursiva consensual comunicativa y la racionalidad instrumental-estratégica, se basa en una anticipación contrafactual de relaciones ideales; éstas, en el nivel de la "comunidad de comunicación real», en todo caso pueden realizarse de manera suficiente, mas nunca completamente. En el discurso argumentativo, sin embargo, las condiciones ideales de comunicación tienen que suponerse suficientemente realizadas. Pero aquí también se da, según la posibilidad y la necesidad, la ya mencionada separación analítica entre los "verdaderos" interlocutores, con los que se puede discutir todo, sin reserva, y aquellos numerosos representantes de la posición estratégica, sobre los que se puede discutir.

Esto significa: en el nivel filosóficamente no falseable del discurso estratégicamente sin condiciones, y sólo en este nivel se puede, si es posible fundamentar con qué y cómo, según la situación, se puede y debe oponer a la racionalidad estratégica del cínico; con la racionalidad contraestratégica, y esto según un principio regulador de la responsabilidad de las consecuencias, que a mi manera de ver debería orientarse a su vez en dos criterios que proporcionaré en seguida: en el objetivo lejano de la realización aproximativa de las relaciones de una comunidad ideal de comunicación (abundaré en esto más tarde) y en la condición restrictiva de no poner en peligro en este camino las conquistas previas de la humanidad (como ejemplo nombro aqui el estado democrático de derecho y constitucional). (Los diferentes intentos de liberar al proletariado —o al pueblo- por medio de una «dictadura del proletariado $\longrightarrow$ del pueblo- han violado este segundo criterio.)

Así se muestra en este lugar que la ética del discurso como ética de responsabilidad referida a la historia, parte del a priori dialéctico de interrelación de la comunidad de comunicación real e ideal que habrá que realizar progresivamente y contiene absolutamente a priori la demanda de una fundamentación racional de la ética de la liberación, mientras no puede pensarse al contrario, a mi manera de ver. La ética de la liberación está en todo su derecho cuando sospecha ingenuidad o hasta cinismo en la 
tradicional ética europea de principios (deontológica y abstraída de la historia), que cree poder partir de un punto cero ficticio en la historia o de la ficción de un nuevo comienzo absoluto y cree poder solucionar el problema de la institución de una sociedad ejusta" o "buena".

Estimo, por ejemplo que todo el debate «liberalismo $v s$. comunitarismos que está teniendo lugar en el mundo angloamericano sufre de este déficit de globalización determinado por la abstracción al que acabo de aludir. Ahí se pregunta con una ingenuidad considerable por las condiciones de constitución y de legitimación de una «sociedad moderna» y se pasa por alto a propósito el hecho de que cualquier sociedad moderna del Norte mantiene relaciones concretas y relevantes en materia política, económica y de derecho internacional con todas las demás sociedades del mundo, entre éstas y no en último lugar - desde la época de la colonización y del subsiguiente imperialismo con los llamados "países en vías de desarrollon del Tercer Mundo.

\subsection{Intento de una estimación realista de la situación que guarda.} el problema del «conflicto Norte-Surs desde el punto de vista de la ética del discurso

En mis comentarios anteriores sobre la posición de la ética del discurso espero haber clarificado el que ésta prevé en su parte $B$ de fundamentacion absolutamente una respuesta al "cínico" a quien Dussel presupone como adversario o contrincante de la ética de la liberación. Hasta me parece que la ética del discurso puede valorar de manera más realista que la ética de la liberación la situación problemática que resulta -en el nivel de una ética política de responsabilidad de no poder suponer sin más la buena fe para un arreglo discursivo-comunicativo de todos los conflictos de intereses. Se entiende que el "cínico" construido por Dussel -así como el "escépticos radical, no sean más que una construcción ideal útil para fines argumentativos. Suponer al «cínico» como el contrincante real de la filosofía de la liberación en el conflicto Norte-Sur, significaria una denuncia total, hasta una demonología de los contrincantes, y una estrategia asi sería una irresponsabilidad ética y estratégica.

Justamente si algo debe cambiar y mejorar hay que tener en cuenta que la división de la tierra en el sentido del conflicto Norte-Sur representa ya una simplificación monstruosa, si bien a veces muy útil. (Esto lo abordé espero suficientemente en mi uintroducción» a la discusión presente.) Aparte de esto, no se puede ni pensar que los representantes de los intereses del Norte en los gobiernos, en las empresas multinacionales, en el Banco Mundial, en el Fondo Monetario Internacional, hasta posiblemente los numerosos científicos que se ocupan de la teoría económica del desarrollo, todos sean cínicos conscientes - una especie de encarnación del diablo 
gnóstico. Esto ni siquiera en el sentido que ellos pudieran limitar las condiciones éticas comunicativas de la propia identidad de manera consecuente con su respectivo "sistema de totalidad". Sin embargo, creo también justificada la caracterización siguiente de Dussel —ciertamente en el sentido de una acusación ética que, en secreto, justamente no cuenta con el cinico total: "Se conoce muy bien el poder, la riqueza y la cultura del grupo dominante, al que uno pertenece, se disfruta y se afirma. Igualmente se sabe la humillación, la debilidad, la incultura y la fealdad del pobre al que se desprecia. Así, el dominador se responsabiliza diariamente de nuevo como persona y como individuo por el pecado original - ya que todos los días dice sí a sus privilegios y posibilidades».

Pero esta caracterización acusatoria (que me «llega bajo la piel») no me parece irreconciliable con la siguiente estimación que haría yo desde la perspectiva de la parte $B$ de la ética del discurso: leyendo hoy día los comentarios en la prensa con respecto a todas las conferencias Norte-Sur, la mayoría de las veces da la impresión de que todos parecen haber entendido y aceptado las normas básicas de una ética del discurso. (Si alguien, por ejemplo un británico, dice que ya es hora de volver a declararse sinceramente a favor de la política clásica de intereses de los estados nacionales, se le contesta usualmente - por lo menos hasta ahora- con indignación.) ¿Deberíamos ahora nosotros, los filósofos, reaccionar cínicamente a este juego humanitario de palabras en los medios para demostrar que comprendemos las intenciones de este juego?

Yo creo que no. Más bien se trata de reconocer claramente en el sentido de la parte $B$ de la ética del discurso que en la realidad política y económica de nuestro tiempo tienen lugar conferencias sobre las cuestiones de la humanidad casi a diario - en todos los niveles de expertos, desde la política y la economía hasta la filosofía esotérica- y estas conferencias - por lo menos las políticamente relevantes- están supeditadas a dos criterios de racionalidad muy diferentes: por un lado se está obligado a la idea reguladora del discurso práctico en el que hay que tomar en cuenta los intereses de todos los afectados en el sentido de la conciencia ética de muchos de los participantes, pero también en el sentido de la pretensión necesaria ante la opinión pública internacional; por el otro lado se sabe $-\mathrm{y}$ se tiene que mantener consciente y responsablemente- que todas estas conferencias tienen también el carácter de negociaciones estratégicas, en las que hay que actuar como representante de intereses.

Bajo estas condiciones que, en mi opinión, representan un progreso frente a la política clásica de intereses, el representante de intereses éticamente responsable tendrá que actuar conforme a los criterios mencionados en la parte $B$ de la ética del discurso. Esto es válido, en primer lugar, para ambas partes del conflicto de intereses existente entre los pobres y los ricos, entre los poderosos y los que casi no tienen poder. También el margen de 
acción de los mejor intencionados representantes de los ricos y poderosos está limitado por los criterios del posible éxito. Más aún, el representante de los pobres y oprimidos tiene, de manera general, la prerrogativa ética y la obligación de compensar estratégicamente las desventajas estructurales - históricamente determinadas- de la propia parte. Justamente esta compensación es el objetivo de la realización a largo plazo de las condiciones político-sociales para la realización gradual de las relaciones de una comunidad ideal de comunicación, postuladas en la parte $A$ de la ética del discurso.

\section{BIBLIOGRAFIA DE REFERENCIA}

APEL, Karl-Otto (1990): «Diskursethik als Verantwortungsethik», en Fornet-Betancourt, 1990, pp. 10-40 ( «La ética del discurso como ética de la responsabilidad», en castellano en Fomet-Betancourt, 1990, pp. 11-44).

- (1992): 1. «Die Diskursethik vor der Herausforderung der Philosophie der Befreiung. Versuch einer Antwort an Enrique Dusseln, en Fomet-Betancourt, 1992, pp. 16-54.

- (1994): 2. a ética do discurso em face do desafio da filosofia da libertação latino-americanaw, en Fomet-Betancourt, 1994 (Ed. Unisinos, pp. 19-39).

Dussel, E. (1990): «La Introducción de la Transformación de la filosofta de K.-O. Apel y la filosofía de la liberación*, en castellano en Fornet-Betancourt, 1990, pp. 45-104 («Die Lebensgemeinschaft und die Interpellation des Armen. Die Praxis der Befreiung», sólo el $\$ 4$ del texto castellano, en Fornet-Betancourt, 1990, pp. 69-96).

- (1991): «La razón del Otro. La interpelación como acto de habla", en Anthropos (Caracas) (enero-julio 1991), pp. 5-41 („Die Vernunft des Anderen. Die Interpellation als Sprechakt», en Fornet-Betancourt, 1992, pp. 96-121).

- (1992): "Del escéptico al cínico», Signos (México), 6.7 (1992), pp. 89.103 («Vom Skeptiker zum Zyniker. Vom Gegner der Diskursethik zu dem der Befreiungsphilosophie», en Fornet-Betancourt, 1993, pp. 55-65).

- (1993): «Hacia un diálogo filosófico Norte-Sur (Algunos temas de discusión entre la Etica del Discurso y la filosofia de la liberación) w ( $\alpha$ Auf dem Weg zu einem philosophischen Nord-Süd-Dialog», en A. Dorschel y M. Kettner et al. [eds.], Transzendental-pragmatik, Francfort, Suhrkamp, pp. 378-396).

- (1994); «Respuesta inicial a K.-O. Apel y P. Ricoeur», en alemán en Fornet-Betancourt, 1994 (en portugués en edición del Goethe Institut, de Porto Alegre).

ForNet-BETANCOURT, Raúl (ed.) (1990); Ethik und Befreiung, Aachen, Augustinus (en castellano en K.-O Apel, E. Dussel y R. Fomet, Fundamentación de la ética y filosofía de la liberación, México, Siglo XXI, 1992), I Seminario de Friburgo, 1989.

- (ed.) (1992): Diskursethik oder Befreiungsethik?, Aachen, Augustinus (en castellano, en Mexico, Siglo XXI, 1994), II Seminario de México, 1991.

- (ed.) (1993): Die Diskursethik und ihre tateinamerikanische Kritik, Aachen, Augustinus (publicado en castellano parcialmente en Dussel, 1994), III Seminario de Maguncia, 1992.

- (ed.) (1994): a publicarse en alemán próximamente el Seminario de São Leopoldo, en Aachen, Augustinus (ya publicado en portugués en Antonio Sidekum [ed.], Éticn do discurso e filosofia da libertaçăo. Modelos complementares, São Leopoldo, Unisinos, 1994, de donde citamos; se publicarán otros materiales del Seminario en portugués por el Goethe Institut de Porto Alegre), IV Seminario de São Leopoldo, 1993.

SCHELKSHORN, Hans (1992): Ethik der Befreitung. Einführung in die Philosophie Enrique Dussels, Friburgo, Herder. 